Int. Journal of Math. Analysis, Vol. 7, 2013, no. 44, 2171 - 2179

HIKARI Ltd, www.m-hikari.com

http://dx.doi.org/10.12988/ijma.2013.36156

\title{
Coincidence and Fixed Point Theorems for Expansive Maps in $d$-Metric Spaces
}

\author{
A. Muraliraj \\ P.G. and Research Department of Mathematics \\ Urumu Dhanalakshmi College, Kattur \\ Tiruchirappalli-620 019 \\ Tamilnadu, India \\ R. Jahir Hussain \\ P.G. and Research Department of Mathematics \\ Jamal Mohamed College(Autonomous) \\ Tiruchirappalli-620 020 \\ Tamilnadu, India
}

Copyright (C) 2013 A. Muraliraj and R. Jahir Hussain. This is an open access article distributed under the Creative Commons Attribution License, which permits unrestricted use, distribution, and reproduction in any medium, provided the original work is properly cited.

\begin{abstract}
In this paper, we establish some common fixed point and common coincidence point theorems for expansive type mappings in the setting of dislocated metric spaces. Also, we introduce some examples to support the validity of our results. The presented results extend and complement some known existence results from the literature.
\end{abstract}

Mathematics Subject Classification: 54H25, 47H10, 47H09

Keywords: Fixed point, Coincidence point, Dislocated metric linear space

\section{Introduction}

In recent years, several authors (see [1-6]) have studied the strong convergence to a fixed point with contractive constant in dislocated metric spaces. P.Hitzler 
and A. K. Seda [8] introduced the notion of dislocated metric space in which self distance of a point need not be equal to zero. They also generalized the famous Banach contraction principle in this space. The study of common fixed points of mappings in dislocated metric space satisfying certain contractive conditions has been at the center of vigorous research activity. In this paper we establish some common fixed point and common coincidence point theorems for expansive type mappings in the setting of dislocated metric spaces.

\section{Preliminary Notes}

Definition 2.1. Let $X$ be a nonempty set, let $d: X \times X \rightarrow[0, \infty)$ be a function satisfying following conditions.

(i) $d(x, y)=d(y, x)=0$ implies $x=y$,

(ii) $d(x, y) \leq d(x, z)+d(z, y)$ forall $x, y, z \in X$.

(iii) $d(x, y)=d(y, x)$ forall $x, y \in X$.

Then $d$ is called a dislocated metric spaces or d-metric on $X$.

Definition 2.2. A sequence $\left\{x_{n}\right\}$ in dislocated metric spaces $(X, d)$ is said to be a Cauchy sequence if for given $\epsilon>0$, there exists $n_{0} \in N$ such that $\forall m, n \geq n_{0}$, implies $d\left(x_{m}, x_{n}\right)<\epsilon$.

Definition 2.3. A sequence $\left\{x_{n}\right\}$ in dislocated metric spaces $(X, d)$ is said to be a Convergent to $x$ if $\lim _{n \rightarrow \infty} d\left(x_{n}, x\right)=0$.

In this case, $x$ is called limit of $\left\{x_{n}\right\}$ and we write $x_{n} \rightarrow x$.

Definition 2.4. A dislocated metric spaces $(X, d)$ is said to be a Complete if every cauchy sequence is convergent in $X$.

Definition 2.5. Let $T$ and $S$ be self maps of a set $X$. If $w=T x=S x$ for some $x \in X$, then $x$ is called a coincidence point of $T$ and $S$, and $w$ is called a point of coincidence of $f$ and $g$.

Example 2.6. Take $X=[0,1], S x=x^{3}, T x=\frac{x^{2}}{2}$. It is clear that 0 and $\frac{1}{2}$ are two point of coincidence and 0 is the unique common fixed point.

\section{Main Results}

Theorem 3.1. Let $(X, d)$ be a dislocated metric space. Let $T$ and $S$ are mappings from $X$ to $X$ and satisfying:

$d(T x, T y) \geq \alpha[d(S x, T x)+d(S y, T y)]+\beta[d(S x, S y)+d(T x, T y)]+d(S x, T y)$

for all $x, y \in X$ where $\alpha+\beta>\frac{1}{2}$, with $\alpha, \beta>0$. Suppose the following hypotheses: 
(i) $S X \subseteq T X$.

(ii) $T X$ is a complete subspace of $X$.

Then $T$ and $S$ have a coincidence point in $X$.

Proof. Let $x_{0}$ be an arbitrary point in $X$. Since $S X \subseteq T X$, there exists a point $x_{1} \in X$ such that $T x_{1}=S x_{0}$. Again,we can choose $x_{2} \in X$ such that $T x_{2}=S x_{1}$. Continuing in the same way, we construct a sequence $\left\{x_{n}\right\} \in X$ such that $T x_{n+1}=S x_{n}$. For all $n \in N \cup\{0\}$.

If $S x_{m-1}=S x_{m}$ for some $m \in N$, then $T x_{m}=S x_{m}$. Thus $x_{m}$ is a coincidence point of $T$ and $S$.

Now, assume that $x_{n-1} \neq x_{n}$ for all $n \in N$.

$$
\begin{aligned}
d\left(S x_{n-1}, S x_{n}\right) & =d\left(T x_{n}, T x_{n+1}\right) \\
& \geq \alpha\left[d\left(S x_{n}, T x_{n}\right)+d\left(S x_{n+1}, T x_{n+1}\right)\right]+\beta\left[d\left(S x_{n}, S x_{n+1}\right)+d\left(T x_{n}, T x_{n+1}\right)\right] \\
& +d\left(S x_{n}, T x_{n+1}\right) \\
& =\alpha\left[d\left(S x_{n}, S x_{n-1}\right)+d\left(S x_{n+1}, S x_{n}\right)\right]+\beta\left[d\left(S x_{n}, S x_{n+1}\right)+d\left(S x_{n-1}, S x_{n}\right)\right] \\
& +d\left(S x_{n}, S x_{n}\right) \\
& =(\alpha+\beta) d\left(S x_{n}, S x_{n-1}\right)+(\alpha+\beta) d\left(S x_{n+1}, S x_{n}\right)
\end{aligned}
$$

Thus we get

$$
(1-\alpha-\beta) d\left(S x_{n-1}, S x_{n}\right) \geq(\alpha+\beta) d\left(S x_{n}, S x_{n+1}\right)
$$

Which implies that

$$
d\left(S x_{n}, S x_{n+1}\right) \leq L d\left(S x_{n-1}, S x_{n}\right) \text { where } L=\left(\frac{1-\alpha-\beta}{\alpha+\beta}\right)<1 .
$$

In general we get,

$$
d\left(S x_{n}, S x_{n+1}\right) \leq L^{n} d\left(S x_{0}, S x_{1}\right)
$$

Now, for positive integer $m$ and $n$ with $m>n \geq 1$, it follows

$$
\begin{aligned}
d\left(S x_{n}, S x_{m}\right) & \leq d\left(S x_{n}, S x_{n+1}\right)+d\left(S x_{n+1}, S x_{n+2}\right)+\ldots \ldots+d\left(S x_{m-1}, S x_{m}\right) \\
& \leq L^{n} d\left(S x_{0}, S x_{1}\right)+L^{n+1} d\left(S x_{0}, S x_{1}\right)+\ldots \ldots+L^{m-1} d\left(S x_{0}, S x_{1}\right) \\
& \leq\left(\frac{L^{n}}{1-L}\right) d\left(S x_{0}, S x_{1}\right)
\end{aligned}
$$

Since $0 \leq L<1$, we get $\left(\frac{L^{n}}{1-L}\right) d\left(S x_{0}, S x_{1}\right) \rightarrow 0$ as $n \rightarrow \infty$. for all $m>n$. Therefore $\left(T x_{n}\right)$ is a cauchy sequence in $(T X, d)$. Since $(T X, d)$ is a complete 
dislocated metric space, there is $z \in X$ such that $\left(T x_{n}\right)$ converges to $T z$ as $n \rightarrow+\infty$. Hence $S x_{n}$ converges to $T z$ as $n \rightarrow+\infty$. Since $\alpha+\beta>1 / 2$, we have $\alpha, \beta$ are not all 0 . So if $\alpha \neq 0$ we get,

$d\left(T x_{n}, T z\right) \geq \alpha\left[d\left(S x_{n}, T x_{n}\right)+d(S z, T z)\right]+\beta\left[d\left(S x_{n}, S z\right)+d\left(T x_{n}, T z\right)\right]+d\left(S x_{n}, T z\right)$

Hence $d\left(S x_{n}, S z\right) \leq\left(\frac{1}{\alpha}\right) d\left(T x_{n}, T z\right)$

As $n \rightarrow+\infty$, and by uniqueness of limit, we have $T z=S z$. Therefore $T$ and $S$ have a coincidence point.

Similarly, for $\beta \neq 0$ we can show that $T$ and $S$ have a coincidence point.

Theorem 3.2. Let $(X, d)$ be a dislocated metric space. Let $T, S: X \rightarrow X$ be mappings satisfying:

(i) $d(T x, T y) \geq \alpha[d(S x, S y)+d(S x, T y)]+\beta d(S x, T x)+\gamma d(S y, T y)$ for all $x, y \in X$ where $\alpha, \beta, \gamma>0$ with $\alpha+\beta+\gamma>1$.

(ii) $\beta<1$ or $\gamma<1$.

(iii) $S X \subseteq T X$.

(iv) $T X$ is a complete subspace of $X$.

Then $T$ and $S$ have a coincidence point in $X$.

Proof. Let $x_{0}$ be an arbitrary point in $X$. Since $S X \subseteq T X$, there exists a point $x_{1} \in X$ such that $T x_{1}=S x_{0}$. Again,we can choose $x_{2} \in X$ such that $T x_{2}=S x_{1}$. Continuing in the same way, we construct a sequence $\left\{x_{n}\right\} \in X$ such that $T x_{n+1}=S x_{n}$. For all $n \in N \cup\{0\}$.

If $S x_{m-1}=S x_{m}$ for some $m \in N$, then $T x_{m}=S x_{m}$. Thus $x_{m}$ is a coincidence point of $T$ and $S$.

Now, assume that $x_{n-1} \neq x_{n}$ for all $n \in N$.

Suppose $\beta<1$.

$$
\begin{aligned}
d\left(S x_{n-1}, S x_{n}\right) & =d\left(T x_{n}, T x_{n+1}\right) \\
& \geq \alpha\left[d\left(S x_{n}, S x_{n+1}\right)+d\left(S x_{n}, T x_{n+1}\right)\right]+\beta d\left(S x_{n}, T x_{n}\right)+\gamma d\left(S x_{n+1}, T x_{n+1}\right) \\
& =\alpha\left[d\left(S x_{n}, S x_{n+1}\right)+d\left(S x_{n}, S x_{n}\right)\right]+\beta d\left(S x_{n}, S x_{n-1}\right)+\gamma d\left(S x_{n+1}, S x_{n}\right)
\end{aligned}
$$

Thus we get

$$
(1-\beta) d\left(S x_{n-1}, S x_{n}\right) \geq(\alpha+\gamma) d\left(S x_{n}, S x_{n+1}\right)
$$

Which implies that

$$
d\left(S x_{n}, S x_{n+1}\right) \leq L d\left(S x_{n-1}, S x_{n}\right) \text { where } L=\left(\frac{1-\beta}{\alpha+\gamma}\right)<1
$$


Suppose $\gamma<1$.

$$
\begin{aligned}
d\left(S x_{n}, S x_{n-1}\right) & =d\left(T x_{n+1}, T x_{n}\right) \\
& \geq \alpha\left[d\left(S x_{n+1}, S x_{n}\right)+d\left(S x_{n+1}, T x_{n}\right)\right]+\beta d\left(S x_{n+1}, T x_{n+1}\right)+\gamma d\left(S x_{n}, T x_{n}\right) \\
& =\alpha\left[d\left(S x_{n+1}, S x_{n}\right)+d\left(S x_{n+1}, S x_{n-1}\right)\right]+\beta d\left(S x_{n+1}, S x_{n}\right)+\gamma d\left(S x_{n}, S x_{n-1}\right) \\
& \geq \alpha d\left(S x_{n}, S x_{n-1}\right)+\beta d\left(S x_{n+1}, S x_{n}\right)+\gamma d\left(S x_{n}, S x_{n-1}\right)
\end{aligned}
$$

Thus we get

$$
(1-\alpha-\gamma) d\left(S x_{n}, S x_{n-1}\right) \geq \beta d\left(S x_{n+1}, S x_{n}\right)
$$

Which implies that

$$
d\left(S x_{n+1}, S x_{n}\right) \leq L d\left(S x_{n}, S x_{n-1}\right) \text { where } L=\left(\frac{1-\alpha-\gamma}{\beta}\right)<1 .
$$

By (1) and (2), in general we get,

$$
d\left(S x_{n}, S x_{n+1}\right) \leq L^{n} d\left(S x_{0}, S x_{1}\right)
$$

Now, for positive integer $m$ and $n$ with $m>n \geq 1$, it follows

$$
\begin{aligned}
d\left(S x_{n}, S x_{m}\right) & \leq d\left(S x_{n}, S x_{n+1}\right)+d\left(S x_{n+1}, S x_{n+2}\right)+\ldots \ldots+d\left(S x_{m-1}, S x_{m}\right) \\
& \leq L^{n} d\left(S x_{0}, S x_{1}\right)+L^{n+1} d\left(S x_{0}, S x_{1}\right)+\ldots \ldots+L^{m-1} d\left(S x_{0}, S x_{1}\right) \\
& \leq\left(\frac{L^{n}}{1-L}\right) d\left(S x_{0}, S x_{1}\right)
\end{aligned}
$$

Since $0 \leq L<1$, we get $\left(\frac{L^{n}}{1-L}\right) d\left(S x_{0}, S x_{1}\right) \rightarrow 0$ as $n \rightarrow \infty$. for all $m>n$. Therefore $\left(T x_{n}\right)$ is a cauchy sequence in $(T X, d)$. Since $(T X, d)$ is a complete dislocated metric space, there is $z \in X$ such that $\left(T x_{n}\right)$ converges to $T z$ as $n \rightarrow+\infty$. Hence $S x_{n}$ converges to $T z$ as $n \rightarrow+\infty$. Since $\alpha+\beta+\gamma>1$, we have $\alpha, \beta$ and $\gamma$ are not all 0 . So we have the following cases

Case1: If $\alpha \neq 0$

$d\left(T x_{n}, T z\right) \geq \alpha\left[d\left(S x_{n}, S z\right)+d\left(S x_{n}, T z\right)\right]+\beta d\left(S x_{n}, T x_{n}\right)+\gamma d(S z, T z)$

Hence $d\left(S x_{n}, S z\right) \leq\left(\frac{1}{\alpha}\right) d\left(T x_{n}, T z\right)$

As $n \rightarrow+\infty$, and by uniqueness of limit, we have $T z=S z$. Therefore $T$ and $S$ have a coincidence point.

Case 2: If $\beta \neq 0$, then $d\left(T z, T x_{n}\right) \geq \alpha\left[d\left(S x_{n}, S z\right)+d\left(S x_{n}, T z\right)\right]+$ $\beta d(S z, T z)+\gamma d\left(S x_{n}, T x_{n}\right) \geq \beta d(S z, T z)$. Hence $d(S z, T z) \leq \frac{1}{\beta} d\left(T x_{n}, T z\right)$. As similar proof of Case (1), we can show that $S z=T z$. Thus $\mathrm{S}$ and $\mathrm{T}$ have a coincidence point. 
Case 3: If $\gamma \neq 0$, then $d\left(T x_{n}, T z\right) \geq \alpha\left[d\left(S x_{n}, S z\right)+d\left(S x_{n}, T z\right)\right]+$ $\beta d\left(S x_{n}, T x_{n}\right)+\gamma d(T z, S z) \geq \gamma d(S z, T z)$. Hence $d(S z, T z) \leq \frac{1}{c} d\left(T x_{n}, T z\right)$. As similar proof of Case (1), we can show that $S z=T z$. Thus $S$ and $T$ have a coincidence point.

Corollary 3.3. Let $(X, d)$ be a dislocated metric space. Let $T, S: X \rightarrow X$ be mappings satisfying:

(i) $d(T x, T y) \geq \alpha d(S x, S y)+\beta d(S x, T x)+\gamma d(S y, T y)$ for all $x, y \in X$ where $\alpha, \beta, \gamma>0$ with $\alpha+\beta+\gamma>1$.

(ii) $\beta<1$ or $\gamma<1$.

(iii) $S X \subseteq T X$.

(iv) $T X$ is a complete subspace of $X$.

Then $T$ and $S$ have a coincidence point in $X$.

Corollary 3.4. Let $(X, d)$ be a dislocated metric space. Let $T, S: X \rightarrow X$ be mappings satisfying:

(i) $d(T x, T y) \geq \alpha d(S x, S y)+\beta d(S x, T x)$ for all $x, y \in X$ where $\alpha, \beta>0$ with $\alpha+\beta>1$.

(ii) $\beta<1$.

(iii) $S X \subseteq T X$.

(iv) $T X$ is a complete subspace of $X$.

Then $T$ and $S$ have a coincidence point in $X$.

Corollary 3.5. Let $(X, d)$ be a dislocated metric space. Let $T, S: X \rightarrow X$ be mappings satisfying:

(i) $d(T x, T y) \geq \alpha d(S x, S y)$ for all $x, y \in X$ where $\alpha>1$.

(ii) $S X \subseteq T X$.

(iii) $T X$ is a complete subspace of $X$.

Then $T$ and $S$ have a coincidence point in $X$.

Theorem 3.6. Let $(X, d)$ be a complete dislocated metric space. Let $T$ be surjective mappings from $X$ to $X$ and satisfied $d(T x, T y) \geq \alpha d(x, y)+$ $\beta d(x, T x)+\gamma d(y, T y)$ for all $x, y \in X$ where $\alpha, \beta, \gamma>0$ with $\alpha+\beta+\gamma>1$. Suppose $\beta<1$ or $\gamma<1$. Then $T$ has a fixed point. 
Proof. Follows from Theorem 3.2 by taking $S=I$, the identity map.

Corollary 3.7. Let $(X, d)$ be a complete dislocated metric space. Let $T$ be surjective mappings from $X$ to $X$ and satisfied $d(T x, T y) \geq \alpha d(x, y)$ for all $x, y \in X$ where $\alpha>1$. Then $T$ has a fixed point.

Corollary 3.8. Let $(X, d)$ be a complete dislocated metric space. Let $T$ : $X \rightarrow X$ be a surjective mapping satisfying: $d(T x, T y) \geq \alpha d(x, y)+\beta d(x, T x)$ for all $x, y \in X$ where $\alpha, \beta>0$ with $\alpha+\beta>1$ and $\beta<1$. Then $T$ has a fixed point.

Corollary 3.9. Let $(X, d)$ be a complete dislocated metric space. Let $T$ : $X \rightarrow X$ be a surjective mapping satisfying: $d(T x, T y) \geq \alpha d(x, y)+\beta d(y, T y)$ for all $x, y \in X$ where $\alpha, \beta>0$ with $\alpha+\beta>1$ and $\beta<1$. Then $T$ has a fixed point.

Theorem 3.10. Let $(X, d)$ be a complete dislocated metric space. Let $T$ and $S$ be two surjective mappings from $X$ to $X$, and satisfying the following inequalities

$$
\begin{aligned}
& \text { 1) } \quad d(S x, x) \leq \alpha d(T S x, x)+\beta d(T S x, S x) \\
& \text { 2) } \quad d(T x, x) \leq \alpha d(S T x, x)+\beta d(S T x, T x)
\end{aligned}
$$

for all $x \in X$ where $\alpha, \beta>0$ with $\beta>1-2 \alpha$. If $T$ or $S$ is continuous, then $T$ and $S$ have a common fixed point.

Proof. Let $x_{0}$ be an arbitrary point in $X$. Since $T$ and $S$ are surjective, there exists a point $x_{1} \in X$ such that $T x_{1}=x_{0}$. Again,we can choose $x_{2} \in X$ such that $S x_{1}=x_{2}$. Continuing in the same way, we construct a sequence $\left\{x_{n}\right\} \in X$ such that $x_{2 n}=T x_{2 n+1}$ and $x_{2 n+1}=S x_{2 n+2}$, for all $n \in N \cup\{0\}$.

Now, for $n \in N \cup\{0\}$, we have

$$
\begin{aligned}
& d\left(S x_{2 n+2}, x_{2 n+2}\right) \leq \alpha d\left(T S x_{2 n+2}, x_{2 n+2}\right)+\beta d\left(T S x_{2 n+2}, S x_{2 n+2}\right) \\
& d\left(x_{2 n+1}, x_{2 n+2}\right) \leq \alpha d\left(T x_{2 n+1}, x_{2 n+2}\right)+\beta d\left(T x_{2 n+1}, x_{2 n+1}\right) \\
&=\alpha d\left(x_{2 n}, x_{2 n+2}\right)+\beta d\left(x_{2 n}, x_{2 n+1}\right) \\
& \leq \alpha d\left(x_{2 n}, x_{2 n+1}\right)+\alpha d\left(x_{2 n+1}, x_{2 n+2}\right)+\beta d\left(x_{2 n}, x_{2 n+1}\right) \\
&(1-\alpha) d\left(x_{2 n+1}, x_{2 n+2}\right) \leq(\alpha+\beta) d\left(x_{2 n}, x_{2 n+1}\right) \\
& d\left(x_{2 n+1}, x_{2 n+2}\right) \leq\left(\frac{\alpha+\beta}{1-\alpha}\right) d\left(x_{2 n}, x_{2 n+1}\right)
\end{aligned}
$$

Hence

$$
d\left(x_{2 n+1}, x_{2 n+2}\right) \leq L d\left(x_{2 n}, x_{2 n+1}\right) \quad \text { where } \quad L=\left(\frac{\alpha+\beta}{1-\alpha}\right)<1 .
$$


On other hand, we have

$$
\begin{aligned}
& d\left(T x_{2 n+1}, x_{2 n+1}\right) \leq \alpha d\left(S T x_{2 n+1}, x_{2 n+1}\right)+\beta d\left(S T x_{2 n+1}, T x_{2 n+1}\right) \\
& d\left(x_{2 n}, x_{2 n+1}\right) \leq \alpha d\left(S x_{2 n}, x_{2 n+1}\right)+\beta d\left(S x_{2 n}, x_{2 n}\right) \\
&=\alpha d\left(x_{2 n-1}, x_{2 n+1}\right)+\beta d\left(x_{2 n-1}, x_{2 n}\right) \\
& \leq \alpha d\left(x_{2 n-1}, x_{2 n}\right)+\alpha d\left(x_{2 n}, x_{2 n+1}\right)+\beta d\left(x_{2 n-1}, x_{2 n}\right) \\
&(1-\alpha) d\left(x_{2 n}, x_{2 n+1}\right) \leq(\alpha+\beta) d\left(x_{2 n-1}, x_{2 n}\right) \\
& d\left(x_{2 n}, x_{2 n+1}\right) \leq\left(\frac{\alpha+\beta}{1-\alpha}\right) d\left(x_{2 n-1}, x_{2 n}\right)
\end{aligned}
$$

Hence

$$
d\left(x_{2 n}, x_{2 n+1}\right) \leq L d\left(x_{2 n-1}, x_{2 n}\right) \quad \text { where } \quad L=\left(\frac{\alpha+\beta}{1-\alpha}\right)<1 .
$$

By combining (1) and (2), we have

$$
d\left(x_{n}, x_{n+1}\right) \leq L d\left(x_{n-1}, x_{n}\right) \quad \forall n \in N \cup\{0\} .
$$

In general, we get $d\left(x_{n}, x_{n+1}\right) \leq L^{n} d\left(x_{0}, x_{1}\right)$.

Thus, for $m>n$, we have

$$
\begin{aligned}
d\left(x_{n}, x_{m}\right) & \leq d\left(x_{n}, x_{n+1}\right)+\cdots+d\left(x_{m-1}, x_{m}\right) \\
& \leq\left(L^{n}+\cdots+L^{m-1}\right) d\left(x_{0}, x_{1}\right) \\
& \leq \frac{L^{n}}{1-L} d\left(x_{0}, x_{1}\right) .
\end{aligned}
$$

As $n \rightarrow+\infty$, the sequence $\left\{x_{n}\right\}$ is a Cauchy sequence in the complete dislocated metric space $(X, d)$. Then there exists $z \in X$ such that $x_{\rightarrow} z$ as $n \rightarrow+\infty$. Therefore $x_{2 n+1} \rightarrow z$ and $x_{2 n+2} \rightarrow z$ as $n \rightarrow+\infty$. Without loss of generality, we may assume that $T$ is continuous, then $T x_{2 n+1} \rightarrow T z$ as $n \rightarrow+\infty$. But $T x_{2 n+1}=x_{2 n} \rightarrow z$ as $n \rightarrow+\infty$. Thus, we have $T z=z$. Since $S$ is surjective, there exists $u \in X$ such that $S u=z$. Now, $d(S u, u) \leq$ $\alpha d(T S u, u)+\beta d(T S u, S u)$, implies that $d(z, u) \leq \alpha d(z, u)$. Since $\alpha<1$, we conclude that $d(z, u)=0$. So $z=u$.

Hence $T z=S z=z$.

Therefore $z$ is a common fixed point of $T$ and $S$.

Corollary 3.11. Let $(X, d)$ be a complete dislocated metric space. Let $T$ be a surjective mappings from $X$ to $X$, and satisfying the following inequalities $d(T x, x) \leq \alpha d(T T x, x)+\beta d(T T x, T x)$ for all $x \in X$ where $\alpha, \beta>0$ with $\beta>1-2 \alpha$. If $T$ is continuous, then $T$ has a fixed point.

Proof. Proof of the corollary follows by taking $\mathrm{S}=\mathrm{T}$ in above theorem. 


\section{References}

[1] Branciari, A: A fixed point theorem for mapping satisfying a general contractive condition of integral type. Int J Math Math Sci. 29,(2002) 531536.

[2] L.C. Ceng, S. Al-Homidan, Q.H. Ansari and J.C Yao, An iterative scheme for equlib- rium problems fixed point problems of strict pseudocontraction mappings, Journal of Computational and Applied Mathematics, 223, (2009), 967-974.

[3] P. Hitzler and A. K. Seda, Dislocated Topologies, J. Electr. Engg., 51, (2000), 3-7.

[4] O. Kada, T. Suzuki, W. Takahashi, Nonconvex minimization theorems and fixed point theorems in complete metric spaces, Math. Japon. 44 (1996) 381-391.

[5] Meir.A, Keeler.E : A theorem on contraction mappings. J Math Anal Appl. 28, (1969) 326-329.

[6] C. Mongkolkeha, W. Sintunavarat, P. Kumam, Fixed point theorems for contraction mappings in modular metric spaces, Fixed Point Theory and Applications 2011, 2011:93.

[7] Rakotch, E: A note on contractive mappings. Proc Am Math Soc.13, (1962)459-465 .

[8] W. Sintunavarat, P. Kumam, Gregus type fixed points for a tangential multi-valued mappings satisfying contractive conditions of integral type, Journal of Inequalities and Applications 2011, 2011:3.

[9] R. Shrivastava, Z. K. Ansari and M. Sharma, Some Results on Fixed Points in Dislocated and Dislocated Quasi-Metric Spaces, J. Advance Studies in Topology, 3(1)(2012), 25-31.

[10] K. P. R. Sastry and G. V. R. Babu, Fixed point theorems in metric spaces by altering distances, Bull. Cal. Math. Soc, 90(1998), 175-182.

[11] F. M. Zeyada, G. H. Hassan, and M. A. Ahmed, A Generalization of a fixed point theorem due to Hitzler and Seda in dislocated quasi-metric spaces, The Arabian Journal for science and engineering,Vol. 31,(2005) 111-114.

Received: June 18, 2013 